\title{
Democracia e luta de classes na atual ordem sócio metabólica do capital
}

\author{
Fernando Gaudereto Lamas \\ Colégio de Aplicação João XXIII - Juiz de Fora
}

\author{
Ednéia Alves de Oliveira \\ Universidade Federal de Juiz de Fora (UFJF)
}

\section{Democracia e luta de classes na atual ordem sócio metabólica do capital}

Resumo: Este artigo analisa a relação entre a democracia e o atual estágio de acumulação capitalista, momento em que a democracia encontra-se relegada a um mero discurso retórico, como algo naturalizado, sem reflexão crítica, mera fraseologia burguesa para justificar maior ação do Estado e a institucionalização de aparatos jurídicos e coercitivos. Discute o modo como os grupos econômicos e políticos, que controlam o atual sistema político, compartilham parte do poder que usufruem atualmente, uma vez que tal compartilhamento implica na alteração da própria dinâmica da acumulação de capital.

Palavras-chave: Democracia. Estado. Modo de produção capitalista.

\section{Democracy and Class Struggle in the Current Metabolic Social Order of Capital}

Abstract: This article analyzes the relationship between democracy and the current stage of capitalist accumulation, a moment in which democracy is nothing but mere rhetorical discourse, something that is naturalized, without critical reflection, a mere bourgeois phraseology to justify greater action of the state and the institutionalization of legal and coercive apparatuses. It discusses how economic and political groups that control the current political system share some of the power that they currently utilize, given that this sharing implies an alteration of the very dynamics of capital accumulation.

Keywords: Democracy, State, Capitalist Mode of Production. 


\section{Introdução}

O aparecimento da democracia na Grécia Clássica pouco tem a ver com o surgimento desse sistema político no último quartel do século 18 . Todo o contexto histórico, social, político, cultural e econômico que justificou o desenvolvimento da democracia na Grécia havia simplesmente desaparecido no final dos Setecentos quando foi reivindicado pelos rebeldes norte-americanos ou pelos revolucionários franceses. Independentemente dos motivos que levaram essa palavra a ser novamente evocada nos dois lados do Atlântico, no final do século 18, o importante é frisar que o grupo social que levantou essa palavra estava associado a interesses diversos nos dois lados. Enquanto nos EUA eram os membros de uma fração de classe dominante, especialmente ligados ao tráfico internacional de escravos, que defendiam o rompimento com a Inglaterra e a democracia, para poucos (ZELDIN, ano?), na França o ideal surgiu baseado nos mesmos princípios, mas expandiu-se para abarcar as camadas mais populares da sociedade francesa. Esse radicalismo é explicado por Hobsbawm (2007, p. 96) como fruto de um destemor que, por sua vez, resultava de uma experiência anterior semelhante: "Depois de 1794, ficaria claro para os moderados que o regime jacobino tinha levado a revolução longe demais para os objetivos e comodidades burgueses, exatamente como ficaria claro para os revolucionários que 'o sol de 1793', se fosse nascer de novo, teria que brilhar sob uma sociedade não burguesa". O que houve na relação entre movimentos sociais e democracia foi uma separação de objetivos. Enquanto os movimentos sociais preconizavam a defesa de direitos coletivos, sustentados essencialmente pala lógica jurídica burguesa do sujeito abstrato, a nascente democracia burguesa buscava impedir a expansão dessa luta através de uma regulamentação arbitrária, violenta, mas eficaz em relação ao trabalho, uma vez que doutrinava o trabalhador adequando-o à lógica social da burguesia que inclui uma mudança especialmente na relação com o tempo que, segundo Thompson (1998, p. 272), torna-se moeda de troca, uma vez que "ninguém passa o tempo, mas sim o gasta".

Como destacou Vásquez (2001, p. 85), não podemos deixar de reconhecer que existe sim, uma ligação entre capitalismo e democracia, especialmente na origem de ambos, o final do século 18 , e o contexto em que os dois nasceram e, inicialmente, se desenvolveram. Contudo, "a democracia no sistema atual encontra uma barreira insuperável nas portas das fábricas". A relação entre a produção econômica capitalista e a forma como ela gradativamente extrapolou o ambiente fabril para englobar a sociedade em sua totalidade, tornou impossível sua adequação aos princípios democráticos, pois enquanto estes últimos pressupunham uma relação entre iguais, o capitalismo é um sistema que necessita da miséria social para sua sobrevivência (GALBRAITH, 1989).

A imagem de uma sociedade dividida entre seres humanos vivenciando a plenitude de suas capacidades, sustentada por um verdadeiro exército de párias revoltados com sua própria situação, não se concretizou no início do século 20 em função dos direitos conquistados pelo movimento operário no campo econômico, mas também da extensão desses direitos ao campo político e social, especialmente através da ampliação do direito de voto e do aparecimento das democracias de massa (HOBSBAWM, 2013). Essa ampliação de direitos políticos às camadas populares que antes eram visivelmente excluídas, não pode ser entendida sem levarmos em consideração dois fatores: as pressões da classe trabalhadora organizada e o próprio avanço tecnológico do sistema industrial. Em outras palavras, é a luta de classes que atua como centro dinâmico do desenvolvimento capitalista, colocando ora os trabalhadores à frente das mudanças sociais, políticas e econômicas, através de sua organização sindical e das pressões por ela realizadas, ora o empresariado, mediante a adoção de novas tecnologias que pressionam os trabalhadores a cederem em seus direitos para garantirem seus empregos.

Dentro da perspectiva acima apresentada, o controle do tempo do trabalhador implicava na transformação do tempo em moeda, tal como assinalou Thompson (1998). Essa mudança acarretou, por sua vez, modificações na estrutura administrativa, de controle do trabalho, ampliando as funções de gerenciamento e de administração e, consequentemente, dividindo a categoria entre aqueles que administram e aqueles que são administrados. Essa estrutura permitiu a criação de uma aparente igualdade, pois fazia com que a figura do capitalista, o homem gordo, de chapéu, fumando charuto - que foi tão caricaturada por George Grosz nas décadas iniciais do século 20 - desaparecesse tanto na Sociedade Anônima quanto na estrutura administrativa moderna voltada para uma "tendência (...) de achatar e comprimir a estrutura organizacional no sentido de aproximar a base da cúpula e melhorar as comunicações" (CHIAVENATO, 2003, p. 161). É a respeito desse tipo de sociedade que Galbraith (1985, p. 15) baseou-se para dizer que: "A produção e a renda elevadas, frutos da tecnologia avançada, de uma organização complexa e eficiente e da capacidade de grandes grupos da sociedade fazerem valer suas reivindicações de renda, afastaram grande parte da população das compulsões e pressões das necessidades físicas".

Esse afastamento resultou também em uma lenta, gradual e permanente despolitização, inicialmente do operariado, mas, em um segundo momento, de amplas camadas da sociedade, pois com o afastamento das compulsões e pressões das necessidades físicas veio junto uma política de consenso. Esta política, ao mesmo tempo em que minimizava elementos mais perturbadores do taylorismo, procurava desmassificar a relação 
entre patrão e empregado, tratando o operário como indivíduo, isto é, colocando na prática o sonho de Margaret Thatcher, primeira-ministra do Reino Unido de 1979 a 1990, de que não existe sociedade, apenas homens, mulheres etc., ou seja, apenas indivíduos ligados por contratos. O individualismo desenvolveu-se no seio de uma sociedade sustentada por direitos coletivos, tal como na Europa Ocidental, nos EUA, no Canadá e no Japão. O que estas sociedades não reconheciam é que esse Estado de Bem-estar social baseava-se essencialmente na exploração da mão de obra daqueles países denominados, à época, como Terceiro Mundo. Em outras palavras, era perfeitamente aceitável para uma multinacional que tinha sua base na Alemanha Ocidental, nos EUA, na França ou em qualquer outro país do chamado Primeiro Mundo, realizar concessões a seus trabalhadores, pois poderia explorar outros trabalhadores situados em países onde os mesmos direitos reivindicados no país sede ainda não estavam sendo colocados em questão.

Especialmente após o advento do neoliberalismo, os ataques às percepções coletivistas tornaram-se mais acintosos, uma vez que os direitos trabalhistas não se encaixavam mais na dura realidade orçamentária dos Estados de bem estar social (HOBSBAWM, 1995). Tornou-se comum, a partir desse momento, atacar os discursos combativos, isto é, aqueles que acreditavam em uma sociedade dividida em classes e que, justamente em função disso, defendiam, dada a semelhança provocada pela exploração capitalista do trabalho, a organização da classe operária e dos demais trabalhadores em torno de um objetivo único. Como destacou Linhart (2007, p. 232), "o objetivo era, de fato, substituir as relações conflitantes, antagônicas, por relações mais conviviais e mais consensuais, independentemente das maneiras de trabalhar", em outros termos, por relações despolitizadas.

Nessa perspectiva, a principal intenção desse artigo é analisar as razões desse distanciamento entre os movimentos sociais e a democracia no atual estágio de desenvolvimento do capitalismo.

\title{
O político versus o econômico e a despolitização da democracia
}

Um dos principais fatores para o processo de despolitização da democracia atualmente pode ser encontrado na separação entre o político e o econômico, protagonizada inicialmente pelo liberalismo e acentuada por um determinado ramo da escola clássica inglesa da economia política. Wood (2011, p. 200), analisando as contradições da democracia liberal ainda em seu nascedouro, frisou que:

\begin{abstract}
A essência da 'democracia' moderna não é tanto o fato de ter ela abolido o privilégio ou estendido os privilégios tradicionais à multidão, mas, sim, o fato de ter tomado emprestada uma concepção de liberdade criada para um mundo no qual o privilégio era uma categoria relevante, para aplicar a um mundo em que o privilégio não é um problema. Num mundo em que a condição política ou jurídica não é o determinante principal das nossas oportunidades de vida e em que nossas atividades e experiências estão em grande parte fora do alcance de nossas identidades políticas e legais, liberdade definida nesses termos deixa muita coisa sem explicação.
\end{abstract}

Embora seja fator determinante para se obter uma representação no mundo contemporâneo e apesar de reconhecidamente relevante, esse sistema pouco muda o panorama socioeconômico. O capitalismo pode conviver perfeitamente com a defesa da ampliação da cidadania e dos direitos civis e políticos, pois estes direitos não afetam a lógica da acumulação do capital. Não por acaso assistimos a uma reafirmação de valores como democracia, cidadania e direitos, defendidos pela própria burguesia como algo muito abstrato. Tal como Marx (2009) já havia destacado, promove-se uma dissociação entre democracia e liberdade ou emancipação humana. Para Marx (2009), a concepção de direitos que a burguesia propõe está alicerçada numa farsa assentada nos ideais de liberdade e de igualdade e da propriedade privada. O grande equívoco consistiria em atribuir ao Estado a possibilidade de emancipar os sujeitos sociais dentro de uma ordem burguesa. Porém, ainda segundo Marx (2009), seria impossível conceder liberdade a um grupo ou classe social uma vez que este Estado está comprometido com a defesa de interesses particulares, pois se constitui como Estado burguês, não pode promover a emancipação humana porque está comprometido com os interesses de uma classe específica, detentora dos meios de produção, e que se apropriaram destas fraseologias para a utilizarem como estratégia de dominação.

Tentando elucidar de forma mais clara como estes direitos podem ser apropriados pela burguesia, Marx (2009) anuncia as diferenças entre as premissas do direito do homem e do direito do cidadão. Os direitos sociais surgem como uma forma de separar direitos do cidadão e direitos do homem - formas de reforçar o direito egoísta e mesquinho presente na ordem liberal -, o que sugere que os princípios da igualdade, da liberdade e da segurança são mecanismos para garantir a propriedade privada do burguês, uma vez que é guiada e dirigida pelo Estado burguês, distanciando da questão da genericidade humana (OLIVEIRA, 2015). O direito humano à liberdade, na sociedade burguesa, nada mais é do que o cerceamento da liberdade de um 
homem pelo outro, fazendo com que haja não a realização, mas a limitação de sua liberdade. Representa apenas a liberdade de usufruir dos bens que o homem possui e de exercer o seu direito como proprietário dos meios de produção, não se configurando como uma emancipação humana, mas apenas a emancipação política, circunscrevendo-se a delegar ao Estado a tarefa de garantir a liberdade e os direitos. Do mesmo modo ocorre com os princípios da igualdade, que repousa sobre uma igualdade jurídica considerando iguais todos os homens perante a lei - criada por representantes da burguesia, visto que as representações parlamentares eram direito apenas dos proprietários dos meios de produção e da renda fundiária (OLIVEIRA, 2015). Neste princípio não é mencionada a questão da igualdade econômica, mas apenas jurídica.

De acordo com Engels e Kautsky (2012), a burguesia apenas se apropriou das formas já definidas pelo modo de produção feudal, transferindo o que era de responsabilidade da Igreja para o Estado, e o dogma e o direito divino para o direito humano. Esse processo de secularização colocou por terra a ideia do princípio teológico e fez nascer o direito jurídico, expressão formal da concepção de direito burguês (OLIVEIRA, 2015).

A expansão das formas jurídicas foram extremamente úteis e funcionais ao modo de produção capitalista, estabelecendo as relações de comércio e de intercâmbio. O mesmo ocorre com as relações sociais na medida em que se tornam mais complexas. Marx (2009) enfatiza que os direitos sociais são formas em que o Estado apropria-se da cidadania e a torna instrumento para legitimar os pressupostos do modo de produção capitalista, com leis e regulamentos que objetivam apenas reformar a ordem burguesa, impedindo que a liberdade concreta dos sujeitos se realize. Não por acaso as formas contratuais serão incorporadas pelo proletariado da mesma forma que a concepção de direito jurídico. Nesse sentido, Engels e Kautsky (2012) analisam que a apropriação da concepção do direito jurídico pelo proletariado e suas formas de organização, partidos e sindicatos, buscou ampliar a esfera do direito jurídico para uma igualdade social em uma perspectiva capaz de se diferenciar do direito da burguesia, mas já havia grande preocupação com a influência da ideologia dos direitos, sobretudo dos direitos jurídicos, no movimento operário. É neste movimento de crítica que Engels e Kautsky publicam o ensaio $O$ socialismo jurídico, em 1887, como resposta ao livro de Anton Menger ( $O$ direito ao produto integral do trabalho historicamente exposto, 1886), que tecia duras críticas ao pensamento de Marx. Menger entendia que os problemas sociais poderiam ser ultrapassados de forma pacífica, sem a necessidade de uma luta revolucionária, o que de certa forma agradava setores mais conservadores dos partidos socialistas. Este período foi marcado pela emergência de teses reformistas ou revisionistas no interior dos partidos socialdemocratas ou socialistas da Europa. Dessa forma, o direito jurídico configura-se apenas como mera redução da luta de classes para propostas reformistas ou revisionistas, afinando-se com os interesses da burguesia que não temem em ampliar os direitos políticos e sociais e utilizá-los como forma de enfraquecer ou cooptar a luta de classes. Longe de aproximar a luta dos trabalhadores, a defesa dos direitos jurídicos ou ainda dos direitos sociais ou mesmo da igualdade, é apenas uma forma de defender os pressupostos burgueses e assegurar a dominação de classe. Um exemplo paradigmático é a ascensão das teses reformistas, no final do século 19 e início do século 20, assim como da expansão dos direitos sociais representados pelas políticas e regulamentações trabalhistas. É importante destacar que a luta pela redução da jornada de trabalho e da regulamentação de algumas formas de trabalho se davam na esfera jurídica, exigindo do Estado os instrumentos para sua consolidação. A cada crise do capital surgiam novas formas de assegurar a hegemonia dominante por meio de concepções vulgares de bem-estar e, ao mesmo tempo, revelando a tragédia do movimento operário.

\section{Estado, direitos e capitalismo}

Nos últimos 30 anos temos assistido a um processo de exploração máxima da força de trabalho por meio de jornadas cada vez mais extensas e intensas, permitindo a extração da mais-valia relativa e absoluta Este processo gera o excedente da força de trabalho disponível, contribuindo para manter os níveis de desemprego e, consequentemente, garantir a extração de mais-valia por meio da exploração de trabalho humano, gerando o crescimento da superpopulação relativa. O capitalismo aprofunda o quadro de miséria ao mesmo tempo em que amplia a concentração e centralização da riqueza. Esse quadro social e econômico faz com que o movimento de acumulação capitalista no seu estágio atual apareça como um processo natural e não como uma expressão fundamental da ordem do capital. As políticas neoliberais tendem a resgatar a lógica de um Estado mínimo e politicamente forte para promover as reformas econômicas necessárias a fim de garantir o estágio de acumulação, sempre sem abrir mão do discurso da democracia, dos direitos e da igualdade. Ou seja, ao mesmo tempo em que radicaliza a fraseologia em prol dos princípios democráticos e da defesa dos direitos expulsa e alija milhões de trabalhadores do acesso ao trabalho, cerceia a liberdade de expressão, estimula políticas que contrariam princípios democráticos, retira direitos sociais ao não investir em políticas de saúde, moradia, previdência e educação (OLIVEIRA, 2015). Privatiza serviços públicos, onera a classe trabalhadora com altas 
taxas de juros e impostos elevados, garantindo desta forma o superávit primário. Uma política econômica baseada nas determinações das agências multilaterais que, no atual estágio de acumulação do capital, são as verdadeiras representantes dos interesses políticos e econômicos, pois ditam as regras e a condução da política interna. Assim, a democracia proposta não se materializa, pois, como salientou Borón (1999), não pode existir democracia onde homens e mulheres tenham que vender sua força de trabalho por um prato de comida.

Os movimentos sociais emergentes adotam uma postura de recusa da perspectiva de classe e também das instituições representativas da classe trabalhadora, como sindicatos e partidos políticos. Suas lutas não colidem com a lógica da acumulação capitalista exatamente por se configurarem como lutas identitárias no âmbito das liberdades individuais e na defesa da igualdade (OLIVEIRA, 2015). Colocam suas lutas em prol dos próprios interesses do capitalismo e da acumulação, pois como salientou Lênin (2007), a defesa da igualdade ou do direito igual está assentado no direito burguês, portanto é um direito desigual, que pressupõe uma desigualdade. Ao considerar os indivíduos iguais, estamos apenas estimulando a desigualdade entre eles, pois não consideramos que cada um vive em condições diferentes uns dos outros. Portanto, a primeira medida seria considerar o direito desigual e não igual, para que cada um pudesse ter a fração justa para viver.

Para Marx (2009, p.52), toda emancipação reduz o

... a sociedade burguesa cria a

luta geral do homem contra $o$

homem, do indivíduo contra o indivíduo, uns contra os outros,

pois elimina até a aparência do

nexo geral, permanecendo a

relação de uma coletividade

geral, porém, exclusiva. mundo humano e a as relações existentes ao próprio homem e a emancipação política reduziu o homem a um membro da sociedade burguesa, um indivíduo egoísta e isolado e, por outro lado, o reduz a cidadão, à pessoa moral: "Esse homem, o membro da sociedade burguesa, passa a ser a base, o pressuposto do Estado político. Este o reconhece como tal nos direitos humanos". O reconhecimento do ser social nos direitos gera, como consequência, uma confusão onde se passa a atribuir a práxis política, logo ao Estado, a responsabilidade pelas mazelas sociais, pelo pauperismo, enfim pela contradição entre as classes. Entendemos que a contradição entre as classes decorre do modo de produção capitalista em que impera a propriedade privada dos meios de apropriação privada da riqueza socialmente produzida. Ao responsabilizar o Estado pela existência de problemas sociais, situamos estes problemas em campos onde o Estado não pode ou não deve atuar, onde não cabe a sua responsabilização; por exemplo, no âmbito das leis da natureza que não tem como o Estado intervir, ou na vida privada que não depende do Estado (MACEDO; OLIVEIRA, 2015). De acordo com Marx (2009), portanto, a condição fundamental para a construção de uma sociedade comunista deveria passar necessariamente pela abolição do Estado, por ser este de caráter classista, concepção amplamente respaldada por Lênin (2007, p. 9), quando afirma que o "Estado é o produto e a manifestação do antagonismo inconciliável das classes". Desse modo, o Estado, utilizando-se de aparatos legais, apenas exerce o controle de uma classe sobre outra, garantindo a submissão dos dominados para a defesa da propriedade dos meios de produção. Essa natureza do Estado é apresentada como um processo natural e necessário para ambas as classes, uma vez que o Estado burguês figura como o guardião dos interesses individuais, aparentemente de forma neutra e imparcial, sem qualquer vinculação com interesses de classe. A natureza mistificada do Estado burguês o faz parecer como instrumento de conciliação e de equilíbrio dos interesses de classe. Para Lênin (2007) esse discurso esteve presente na revolução russa de 1917 quando os mencheviques defenderam a necessidade do Estado como agente de conciliação entre as classes sociais, numa perspectiva nitidamente alicerçada na compreensão de uma democracia pequeno burguesa.

O mesmo ocorre com as políticas sociais, adotadas e implementadas pelo Estado, podendo ser definidas pela correlação de forças presentes no interior do próprio Estado, mas sempre com o cuidado de não afetar a lógica da acumulação de capital. De acordo com Del Rosal (2015), nem mesmo em países como a Suécia, onde os direitos e as políticas sociais foram amplamente difundidas e abrangentes, o processo de acumulação recuou, pelo contrário, o reformismo foi um elemento de garantias do capitalismo e da acumulação por meio da legitimação da democracia e da adesão do movimento operário ao sistema institucional. $\mathrm{O}$ mesmo se pode dizer dos demais países onde vigorou o Estado de bem estar social. A perspectiva reformista, de acordo com Oliveira (2013), esteve presente nos anos de crescimento econômico do pós-segunda guerra, momento em que o movimento sindical e os partidos de esquerda organizaram-se em defesa do direito ao emprego, ao salário e ao padrão de consumo estabelecido pelo pacto fordista-keynesiano. As grandes manifestações eram sempre em prol da permanência destes benefícios ou da renovação dos con- 
tratos coletivos de trabalho. Houve a adesão da classe trabalhadora aos processos normativos institucionais, quando passa a delegar ao Estado a tarefa de criar as leis, mudar as constituições, definir impostos, alterar políticas trabalhistas e sociais. O Estado garante sua legitimidade política ao incorporar todos os segmentos sociais na luta pela institucionalidade da ordem. O econômico parece completamente separado do político e as lutas que se travam hoje no interior da sociedade burguesa capitalista parece não ter vinculação alguma com as políticas econômicas adotadas pelos Estados capitalistas. Exemplo paradigmático é quando constatamos as contrarreformas de corte neoliberal em curso na maioria dos países capitalistas do centro e da periferia. A redução dos gastos em políticas sociais, os ataques às leis trabalhistas, a criação dos contratos atípicos e o aumento do desemprego aparecem como medidas necessárias e que devem ser compartilhadas por todos indistintamente. Tudo em nome da recuperação da economia que, no discurso dos apologistas da ordem burguesa, deverá beneficiar a todos.

Nos dias atuais, em que a ofensiva do capital tem mostrado, em todos os cantos do mundo, um recrudescimento da força coercitiva do Estado burguês para garantir os superlucros do capital, assistimos a mudanças substanciais, mesmo nos países desenvolvidos, embora o ritmo e a natureza das medidas sejam mais graduais, suscitando o risco de, num futuro próximo, a extinção da política de bem estar social, dando lugar ao retorno de velhas relações trabalhistas assentadas na total desproteção legal ou social. Por essa razão Chasin (1988) vai considerar a refutação de Marx à leitura feita por Aristóteles e Hegel sobre a ideia da perfectibilidade do Estado, dizendo que todo poder é imperfeito, por isso Marx só pode pensar a sociedade socialista sem a figura do Estado. Essas formulações de Marx, segundo Chasin, já aparece no período de rompimento com os neohegelianos, na revolução de 1844, Alemanha. Marx percebe que era impossível que a democracia fosse alcançada pela revolução burguesa, cabendo somente aos pobres e aos miseráveis tal tarefa. A emancipação humana não pode ser objeto da burguesia, mas apenas do proletariado. Para Chasin (1988), o Estado é a contradição entre público e privado, entre indivíduo e sociedade, entre interesses particulares e interesses gerais. A administração pública tem como alicerce garantir a propriedade privada e nisto o Estado não pode mexer.

Em uma sociedade regida pelo modo de produção capitalista, o limite da emancipação humana está posto por aquele que assumiu para si a responsabilidade de definir e legislar em prol do bem comum, mas na sua essência legisla e favorece apenas interesses classistas e particulares. As políticas sociais serão apenas mecanismos de atingir determinados segmentos, como bem demonstra a ofensiva neoliberal. Por essa razão, as lutas sociais não podem ser recortadas e fragmentadas, pelo contrário, precisam ser colocadas no âmbito das relações de produção e de trabalho, como elemento da mediação da superação da ordem capitalista e não no imediatismo da necessidade egoísta ou identitária do reformismo burguês. Marx e Engels (2009, p. 135) afirmam que a sociedade burguesa cria a luta geral do homem contra o homem, do indivíduo contra o indivíduo, uns contra os outros, pois elimina até a aparência do nexo geral, permanecendo a relação de uma coletividade geral, porém, exclusiva.

Longe aqui de afirmar que devemos abandonar as lutas sociais, o que estamos querendo sugerir é que se faz necessário considerar sobre quais condições e contra quem estamos lutando, caso contrário podemos entender que o inimigo somos nós mesmos e não o Estado burguês e sua representação classista. Podemos instaurar a guerra de todos contra todos, no sentido pleno da proposição hobbesiana, onde tudo é naturalizado e nos afastando da defesa da liberdade e da emancipação humana. É importante recuperar a introdução que Engels (2012), em 1895, faz para As lutas de classes na França, onde pondera que as barricadas não são o único instrumento de luta, mas continua sendo um dos mais importantes.

\section{Considerações finais}

A democracia representativa, tal como a conhecemos atualmente, encontra-se sequestrada por interesses classistas. O sistema democrático encontra seus limites no desejo da ordem sócio metabólica do capital de ampliar ou não os direitos a um número maior de pessoas. O momento atual é de refluxo dos direitos sociais e trabalhistas, já que as pressões por maior flexibilização legislativa encontram eco num cenário de crise do Capital gerada pelo próprio Capital, mas paga pelos trabalhadores. Dentro desse cenário, a possibilidade que se coloca é de ampliar e de radicalizar a luta pela democracia, compreendendo que a atual democracia representativa "não é falsa; é pouca, é insuficiente" (SANTOS, 2016, p. 139), e necessita ser politizada no sentido de que o sistema democrático somente pode se livrar das pressões do Capital quando politiza as relações sociais, ou seja, quando passa a compreender as relações sociais não a partir de um prisma imediatista, economicista, mas de uma lógica sócio-política inclusiva que entende a existência de múltiplas demandas oriundas dos mais diversos setores sociais, que são legítimas e precisam ser levadas em consideração. 
Uma boa forma de colocar um ponto e vírgula (já que não vemos ainda nem sinal de um ponto final nesse debate) é através de uma pequena história contada e analisada por Zizek (2011). A história refere-se à visita que o primeiro ministro chinês, Chu En-lai, fez à Suíça para negociar o fim da Guerra da Coréia. O referido ministro, durante uma entrevista, foi questionado por um jornalista francês sobre o que ele achava da Revolução Francesa, e respondeu: "ainda é cedo demais para dizer". Segundo Zizek (2011, p. 167-168), a desintegração das "democracias populares" durante a década de 1990 trazia à tona, novamente, a luta pelo significado histórico da Revolução Francesa. O fracasso das experiências socialistas deve, portanto ser analisado de maneira semelhante à que procedeu Chu En-Lai, isto é, com cautela, pois ainda é muito cedo para dizermos que o malogro daquela experiência enterrou definitivamente toda e qualquer forma de aprofundamento e/ou de radicalização da democracia.

\section{Referências}

BORÓN, A. Os “novos Leviatãs” e a pólis democrática: neoliberalismo, decomposição estatal e decadência da democracia na América Latina. In: Pós - neoliberalismo II: que Estado para que democracia? Sader, Emir e Gentili, Pablo(orgs.). Petrópolis, RJ: Vozes, 1999. CHASIN, J. Superação do liberalismo. Aulas ministradas durante o curso de pós-graduação em Filosofia Política, promovido pelo Dep. de Filosofia e História da Universidade Federal de Alagoas, de 25/01 a 06/02 de 1988. A transcrição é literal.

CHIAVENATO, I. Introdução à teoria geral da administração. Rio de Janeiro: Elvisier, 2003.

DEL ROSAL, M. C. El capitalismo sueco e los límites del socialismo reformista. Uma crítica marxista del modelo Rehn-Meidner (19321983). Universidad Complutense de Madrid. Tese de doutorado, Madri, 2015.

ENGELS, F. Prefácio. In: MARX, K. As Lutas de Classes na França de 1848 a 1850. Tradução: Nélio Schneider. São Paulo: Boitempo, 2012.

; KAUTSKY, K. O socialismo jurídico.Tradução: Lívia Cotrim e Márcio Bilharinho Naves. São Paulo: Boitempo, 2012.

GALBRAITH, J. K. O novo estado industrial. Tradução: Leônidas Gontijo de Carvalho. São Paulo: Nova Cultural, 1985.

. O pensamento econômico em perspectiva: uma história crítica. Tradução: Carlos Afonso Malferrari. São Paulo: Pioneira, 1989.

HOBSBAWM, E. A era das revoluções (1789-1848). 21 a ed. Tradução: Maria Teresa Lopes Teixeira \& Marcos Penchel. São Paulo: Paz e Terra, 2007.

. A era dos extremos: o breve século XX (1914-1991). Tradução: Marcos Santarrita. São Paulo: Companhia das Letras, 1995.

. Nações e nacionalismo desde 1780: programa, mito e realidade. $6^{a}$ ed. Tradução: Maria Célia Paoli \& Anna Maria Quirino. São

Paulo: Paz \& Terra, 2013.

LÊNIN, V. O Estado e a revolução: o que ensina o marxismo sobre o Estado e o Papel do proletariado na revolução. Tradução: Aristides Lobo. São Paulo: Editora Centauro, 2007.

LINHART, D. A desmedida do capital. Tradução: Wanda Caldeira Brant. São Paulo: Boitempo, 2007.

MACEDO, C; OLIVEIRA, E. A práxis política e a relação do estado na sociedade de classes. In. OLIVEIRA, E. \& LAMAS F. (Orgs). Pensamento crítico e Ciências Humanas: um caminho para Marx. Rio de Janeiro: Editora Lumen Juris, 2015.

MARX, K. Para a questão judaica. Tradução: Jose Barata-Moura. São Paulo: Expressão Popular, 2009.

MARX, K.; FRIEDRCH, E. A sagrada família. Tradução: Marcelo Backes. São Paulo: Boitempo, 2009.

OLIVEIRA, E.A. Classes sociais e reformismo social: estratégia de conciliação entre capital e trabalho. Revista de História Econômica \& Economia Regional Aplicada -HEERA - disponível em http://www.ufjf.br/heera .Vol. 9, nº 15, Julho-dezembro 2013, pág. 150-173.

. Os direitos na ordem burguesa: entre a farsa e a tragédia. In. OLIVEIRA, E. \& LAMAS F. (Orgs). Pensamento crítico e Ciências Humanas: um caminho para Marx. Rio de Janeiro: Editora Lumen Juris, 2015.

SANTOS, Boaventura de Sousa. A difícil democracia: reinventar as esquerdas. São Paulo: Boitempo, 2016.

THOMPSON, E. P. Costumes em comum: estudos sobre a cultura popular tradicional. Tradução: Rosaura Eichemberg. São Paulo: Companhia das Letras, 1998.

WOOD, E. Democracia contra capitalismo: a renovação do materialismo histórico. Tradução: Paulo Cezar Castanheira. São Paulo: Boitempo, 2011.

VASQUEZ, A. S. Entre a realidade e a utopia: ensaios sobre política, moral e socialismo. Tradução: Gilson B. Soares. Rio de Janeiro: Civilização Brasileira, 2001.

ZIZEK, S. Em defesa das causas perdidas. Tradução: Maria Beatriz de Medina. São Paulo: Boitempo, 2011.

\section{Fernando Gaudereto Lamas}

fernando.lamas@ufjf.edu.br

Doutor em História pela Universidade Federal Fluminense (UFF).

Professor do Colégio de Aplicação da Universidade Federal de Juiz de Fora (UFJF). Rua visconde de Mauá 300, Bairro: Santa Helena CEP 36015-260, Juiz de Fora - MG. 


\section{Ednéia Alves de Oliveira}

Doutora em Serviço Social pela Universidade Estadual do Rio de Janeiro (UERJ). Professora do Programa de Pós Graduação em Serviço Social e da Graduação em Serviço Social da Universidade Federal de Juiz de Fora (UFJF).

\section{Colégio Aplicação - UFJF}

Rua visconde de Mauá 300, Santa Helena

Juiz de Fora - Minas Gerais - Brasil

CEP: $36015-260$

\section{UFJF}

Rua José Lourenço Kelmer, s/n, Bairro Martelos

Juiz de Fora - Minas Gerais - Brasil

CEP: 36036-330 